benefits of the contract became evident. Our first audit showed that in $20 \%$ of referrals the referrer had given inadequate information; the second showed that in only $7 \%$ was information inadequate. At the same time there was an increase of $15 \%$ in the complexity of referrals. Similarly, responses to us in writing within six weeks of referral rose from $25 \%$ of cases in the first audit to $60 \%$ in the second. There was also a change in source of referrals - those from district nurses rising by $34 \%$ and those from general practitioners falling by a similar amount. We have no firm data yet on whether delivery of services improved.

To explore relationships between the social services and primary health care teams the psychology department of Plymouth University carried out a questionnaire survey of attitudes. This showed that health visitors had the greatest influence on social workers. It also highlighted a complex network of contracts between the two teams and suggested the need for clear lines of communication. A member of the primary health care team has now been designated liaison officer and all messages are passed to her.

\section{All worth it in the end}

Although the contracting process was complex, it was worth while. We can now deal with the main problems that could arise in the new community care system. The Plymouth Community Trust is considering whether nurses and health visitors could order certain aspects of social care after training by the social services department. The aim is not to increase the community nurses' workload but rather to decrease time spent chasing the social work team.

Many general practitioners fear that the community care reforms will increase their own workload, too. We do not believe that general practitioners will be overburdened. In our practice, covering a population of 10000 , we make an average of 1.7 referrals a week. And we have not been asked to see any patients specifically to help social workers' assessments. We

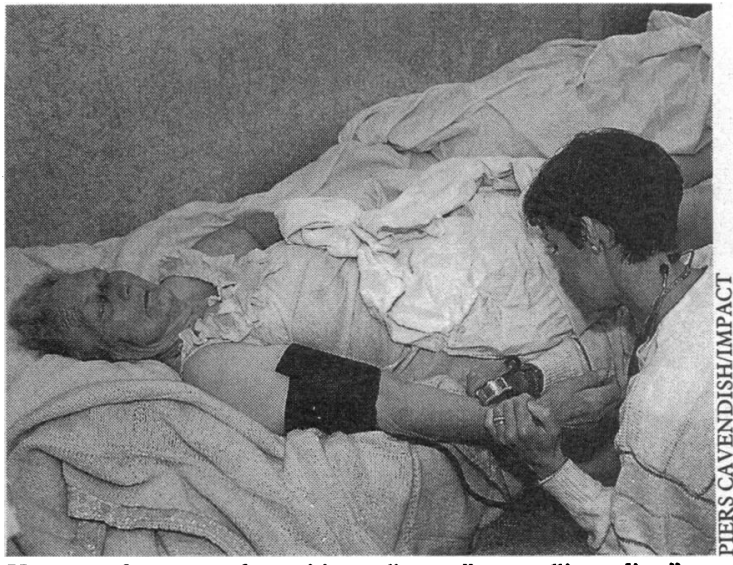

Urgent work: to general practitioners "urgent" means "immediate"

already provide medical notes for patients admitted to county council run residential homes and letters of information for those going to private care. Will there really be much change?

\section{Conclusions}

I have come through this experience with much greater understanding of social workers. I have learnt a lot from them and I recognise that we think and work in different ways. I have also learnt much from the skills of others: without Chris Whitaker and Tess Lomax we might not have succeeded in improving the way we organise community care. Though other practices may interpret and implement the community care reforms in different ways, I hope that some of the lessons we have learnt will be useful. General practitioners do not have to be fundholders to take a contracting approach to improve communication with social workers.

1 NHS Management Executive. General practitioners and "Caring for People." London: HMSO, 1992.

\title{
The fortysomething barrier: medicine and age discrimination
}

\section{Peter Forster}

Agism in the medical profession is mainly covert but it is not uncommon. It is widely believed that people become less productive as they get older. However, research has shown that older people have less absenteeism, more job stability, and greater output than younger workers. Job losses, which until recently were unheard of in the NHS, usually affect older people first, resulting in the loss of those with the most skill and experience. With an aging population it is important that the government takes steps to discourage age discrimination in the NHS and Britain as a whole.

Age related assumptions are made throughout a doctor's career. Subjective and usually implicit their manifestations are obvious. From time expired senior registrar who despairs of finding that elusive consultant job to the frustrations of the mature, would be medical student who comes up against the agist admissions policies of many British medical schools. Sometimes the barriers are explicit. In a letter to regional advisers and postgraduate deans in 1988 the chairman of the Joint Committee on Higher Surgical Training stated that trainees aged 35 or over and without the requisite "papers" should be told they are unlikely to succeed in finding a senior registrar post. The doctors retainer scheme sponsored by the Department of Health, which seeks to help doctors stay in touch with medicine so that they can later return to NHS employment, applies only to doctors under $55 .{ }^{1}$

Mature medical students (defined as over 23) account for only $2 \%$ of the medical school population. Most universities are dubious about accepting students older than 30 . Indeed, in 1990 only $0.42 \%$ of preclinical students were over $30 ; 74 \%$ were aged $18-19 .{ }^{2}$ When a medical career has to be ended early because of staffing reductions (virtually unheard of in the NHS before the reforms but now planned in the wake of the Tomlinson inquiry) age usually predominates over other factors such as experience and skill. Early retirement and voluntary redundancy schemes often result in the loss of some of the best people. A recent report showed how older workers bear the brunt of economic recession. ${ }^{3}$ Older people are always among the first to be made redundant and to retire prematurely yet there is no evidence to show "that redundancy or early retirement are seriously associated with health or any general tendency for workers to become less productive with age." The government, the report adds, "should take a lead by setting a good example in the context of its own 


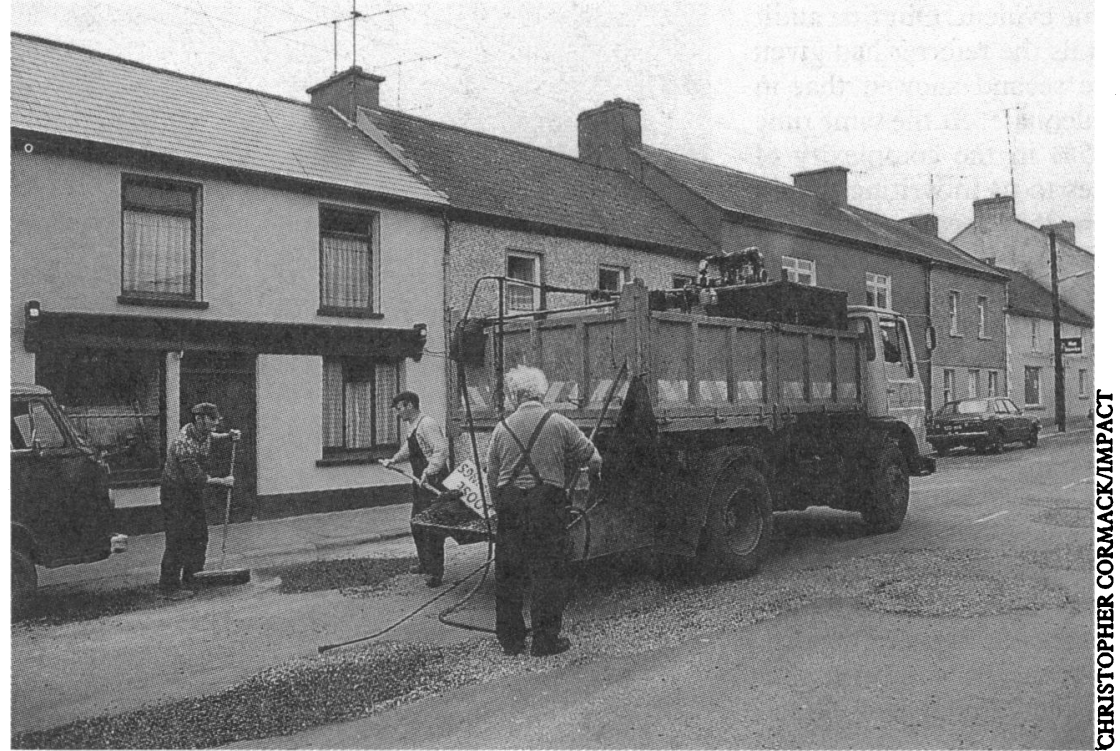

Older workers have as many strengths as younger ones

employees and disseminate the information which enables firms to see the full costs of the permanent loss of their older workers." 3

\section{What is age discrimination?}

Age discrimination is a result of prejudice and stereotyping and hinders the proper consideration of a person's talents, skills, abilities, potential, and experience. Agism, like other forms of discrimination at work, is rooted in a society's culture. The predominant view in Britain and other Western countries associates aging with decline, dependency, isolation, and often poverty. Such negative stereotypes are often reinforced by pervasive media images which portray the young as capable and glamorous.

Arbitrary age discrimination can affect everyone. It consistently disadvantages older workers, young people, and women returning to work. It overwhelmingly favours people aged 25 to 35 . Decisions based on age are rarely justifiable, are often of poor quality, and lead, as the government now recognises, to ineffective use of human resources. In an open letter to members of parliament in 1991 the Metropolitan Authorities Recruitment Agency (METRA) which has led the debate on agism said: "Many people of all ages face unfair discrimination at work or when looking for a job, simply because of their date of birth. Negative beliefs are held about older people. Often these are based upon generalisations. Most are known to be false. These untested beliefs get built into the culture of many organisations."'4

\section{Government response}

The inaugural meeting of the Department of Employment's Advisory Group on Age Discrimination was held in February. Under the chair of employment minister Patrick McLoughlin, the group aims to persuade employers to abandon agist policies and to promote good practice in employment. Michael Forsyth, minister of state for employment, speaking at a recent recruitment industry's award ceremony, said, "blanket age discrimination and recruitment is absurd, wasteful, and shortsighted." He further warned that employers who "set arbitrary age limits are missing out on a variety of skills, experience, and commitment that older workers can bring to a job."

Although the government has ruled out legislation, many organisations are calling for an age discrimination act similar to the existing Race Relations Act 1976 and Sex Discrimination Act 1975 and 1986. In June 1990 an inaugural meeting of the Alliance Against Ageism in Employment launched a "ban agism in recruitment" campaign. The campaign wants legislation to stop the use of upper age limits in recruitment advertising. At least seven private members' bills on the subject have been presented by both Conservative and Labour MPs. Employers' organisations like the Confederation of British Industry and the Institute of Personnel Management have also proposed ways of tackling the problem. Peter Naylor, past vice president of the Institute of Personnel Management and an advocate of legislation, believes that marginalisation of older workers is unlikely to be eliminated simply by exhorting the worth of the people aged 50 and over. As Western Europe's largest employer, the NHS has been noticeably reticent in the debate.

\section{Health and age}

According to Eric Midwinter, former director of the Centre for Policy on Ageing, "Discrimination by age is as vicious as discrimination by race or sex and not borne out by medical evidence." There is no evidence to support the common assumption that older workers are slower and less productive. Indeed workers over 50 have been found to be more productive than their younger colleagues because of their experience, maturity, and strong work ethic.

One study which examined the effects of age and various performance criteria showed that performance, rather than falling with age may actually improve. ${ }^{5}$ While some slowing down undoubtedly occurs with age the effects are greatly exaggerated and can usually be offset by changing the pattern or intensity of the work. An American Department of Health study in 1978 challenged many of the popular beliefs about older people. The study found that the intelligence of most people remains constant until the age of 70 and concluded that "for most people life satisfaction does not decline markedly with age, and the ability to function and adapt does not seem related to age." $\mathrm{A}$ recent study of Open University graduates found that students aged 60 to 65 had better results than any other age group. Other studies show that older workers tend to have fewer accidents, less absenteeism, and greater output and job stability than their younger counterparts. ${ }^{\text {? }}$

Research overwhelmingly supports the proposition that age is a poor predictor of performance and ability. As Naylor says, "there is ample UK evidence which reinforces US studies to show that capacity to learn new skills, acquire knowledge and new attitudes in middle age does not decline sharply after one's 40th birthday." Probably the most important thing which all studies show is the diversity of people. Indeed people may become more diverse with age because of differing life experiences.

\section{Lessons from abroad}

UNITED STATES

In the United States the Age Discrimination Act 1967 aims to "promote the employment of older persons based on their ability rather than their age, to prohibit arbitrary age discrimination in employment, and to help employees and workers find ways of meeting problems arising from the impact of age in employment." The act applies to people aged 40 and over. The act makes it unlawful for an employer to "limit, segregate or classify an employee in any way that would deprive that employee of job opportunities or adversely affect employment status because of their age." In 1978 the act was amended to make the earliest 
mandatory retirement age 70 and to eliminate it entirely for federal employees.

CANADA

In Canada the Human Rights Act 1978 does not go as far as removing mandatory retirement ages (although there is pressure growing to do so) but does make it unlawful to deprive people of employment opportunities on grounds of age, as a result of policies or practices relating to recruitment promotion, training, or other personnel matters.

\section{EUROPEAN COMMUNITY}

In the European Community only France has legislation which protects older workers. In 1989, with support from the minister of culture, the government launched a national day: the journee de flamboyance. $L a$ flamboyance is a new movement which promotes and celebrates longevity. It aims at dispelling the myths about old age and at building a network of associations concerned with the issues of aging.

In 1990 the European parliament voted on two reports calling for action on age discrimination. The de Vitto report on the social charter action programme called for the commission to carry out a survey into legislation and practices that discriminated on the grounds of age and to take measures to guarantee equal treatment for elderly people. The Nianias report on European Commission proposals for older people calls on the commission to conduct investigations into discriminatory practices on the grounds of age and initiate action to bring about equal treatment for elderly people.

\section{Impetus for change}

The main impetus in Britain for measures to deal with age discrimination at the workplace-despite the current recession-derive from the so called demographic time bomb which will be increasingly felt by all organisations, public and private, during the 1990 s and into the next century.

The fall in the birth rate in the 1970s means that the number of people entering the labour market today is falling. For instance there are one million fewer 16 to 19 year olds in 1993 than there were in 1983-a drop of $28 \%$. Other changes highlighted in 1989 by the National Economic Development Council include an aging workforce (in the 1990s the working population will become increasingly concentrated in the middle age groups and in the year 2000 there are likely to be 1.8 million more people aged 35 to 54) and an expanding adult labour force (women returning to the labour market are expected to provide most of the growth in labour force in the 1990s).

In addition, the report shows the changing skills needed by employers. New skills and flexibilities are needed to cope with increasing new technology, the single European market, the internationalisation of markets, changes in the structure and nature of employment, and changes in patterns of consumer demand and the distribution of disposable income. ${ }^{9}$

\section{Time for a rethink}

Proposals for meeting the challenges posed by changes in the workforce and patterns of work include calls for the total elimination of mandatory retirement ages and changes to existing employment laws which discriminate against the over $60 \mathrm{~s}$. The Metropolitan Authorities Recruitment Agency (METRA), which is a consortium of 38 authorities (together employing over 350000 staff), has instigated several campaigns aimed at eliminating age discrimination in local government.

One aspect of METRA's campaign deals with public sector pension rules (similar to those operating in the NHS). Pension abatement has been singled out as a blatant piece of age discrimination that is obsolete and should be abolished. Brian Russell, the principal administrator for the United Kingdom Steering Committee for Local Government Superannuation believes that abatement rules are "illogical and uneconomic. It may be fair enough for those people who retire at 60 or 65 , but consider those who were forced to take early retirement or who were sick and have now recovered."

\section{Conclusions}

This year has been scheduled by the European Commission as European Year of Older People and Solidarity between Generations, and age discrimination and the employment of older workers is emerging as a major public policy issue. In medicine, as in other occupations, there is no significant correlation between age and work performance. Indeed most studies of employment show the low validity and reliability of age as a predictor of performance. The use of age criteria in redundancy and early retirement schemes has resulted in a massive withdrawal of older workers from the British workforce and a considerable loss of skill and talent.

Despite the current recession, demographic changes and the "greying" of the workforce means urgent new thinking is needed on such issues as flexible working and retirement, taxation and superannuation rules (especially abatement provisions), and employment laws. The efficient and effective use of people's skills requires that employment decisions are based on job related criteria-skills, qualifications, potential, and competence-rather than arbitrary, outmoded, and misconceived notions about age.

1 Department of Health and Social Security. Doctors retainer scheme. London: HMSO, 1983.

2 Women in Medicine. Careers for women in medicine: planning and pitfalls. 3rd ed. London: WIM, 1922:6.

3 Employment Institute. Economic report No 2. Vol 6. London: Employment Institute, 1991:10.

4 Metropolitan Authorities Recruitment Agency. Stop Ageism in employment: an open letter to MPs. London: METRA, 1991.

5 US Department of Health, Education, Welfare, and Health Financing. Working with older people: a guide to practice. Vol 1. Washington, DC: US Government Printing Office, 1978.

6 Giniger S, Dispaenzieri A, Eisenber J. The effects of age, experience, and performance on speed and skill in an applied setting. $\mathcal{F}$ Appl Psychol 1983;68:215-23.

7 Waldman DA, Avolio BJ. A meta analysis of age differences in job performance. f Appl Psychol 1986;71:33-8.

8 Naylor P. Age no barrier. London: METRA, 1990:30.

9 National Economic Development Council. Labour market repont with the training agency: defusing the demographic time bomb. London: NEDO, 1989.

\section{Correction}

Trends in health care and their effects on medical education

We regret that we inadvertently did not make clear that some of the material in box three of the article "Trends in health care and their effects on medical education" (23 January, p 255) came from work undertaken at King's College School of Medicine and Dentistry. Further details are available from a table entitled "Implications of personal tutoring on the community based medical firm" by Brian Fine in Community Based Teaching, edited by Angela Towle and published by the King's Fund, and were given in a talk on teaching general medicine in general practice by Paul Booton. Full acknowledgments will appear in the book that will be based on this series. 